\title{
Synthesis and Characterization of mixed ligand complexes of Co(II) ion with some $\mathbf{N}$ and $\mathbf{S}$ donor
}

\author{
Mahesh K. Singh $^{\mathrm{a} *}$, Ranajoy Laskar ${ }^{\mathrm{a}}$, Sanjit Sutradhar ${ }^{\mathrm{a}}$, Bijaya Paul $^{\mathrm{a}}$, \\ S.Bhattacharjee ${ }^{a}$ and Arijit Das ${ }^{\mathrm{b} *}$ \\ ${ }^{a}$ Department of Chemistry, Tripura University, Suryamaninagar-799022, Tripura, India. \\ ${ }^{b}$ Department of Chemistry, Ramthakur College, Agartala-799003, Tripura(w),Tripura, India.
}

\begin{abstract}
Mixed ligand complexes of Co(II) ion with some heterocyclic nitrogen donors and 1,1-dicyanoethylene-2,2-dithiolate of the compositions, $\mathrm{Co}(\mathrm{N}-\mathrm{N})_{2}(\mathrm{i}-\mathrm{MNT}), \quad \mathrm{Co}(\mathrm{N}-\mathrm{N})(\mathrm{i}-\mathrm{MNT}) .2 \mathrm{H}_{2} \mathrm{O}$ and $\operatorname{Co}(N-N)(i-M N T) L_{2}\left[N-N=1,10\right.$-phenanthroline, 2,2'-bipyridine ; $i$-MNT ${ }^{2-}=1,1$-dicyano- ethylene $-2,2-$ dithiolate; $L=$ pyridine (py), $\alpha$-picoline $(\alpha$-pic), $\beta$-picoline $(\beta$-pic) or $\gamma$-picoline $(\gamma$-pic) have been isolated and characterized on the basis of analytical data, molar conductance, magnetic susceptibility, electronic and infrared spectral studies. The molar conductance data reveal non-electrolytic nature of the complexes in DMF. Magnetic moment values suggest low spin complexes. The electronic spectral data suggest distorted octahedral stereochemistry around Co(II) ion in these complexes. Infrared spectral studies suggest bidentate chelating behaviour of i-MNT ${ }^{2-}$, 1,10-phenanthroline and 2,2'-bipyridine while other ligands show unidentate behaviour in their complexes.
\end{abstract}

Keywords: Cobalt(II), 1,1-dicyanoethylene-2,2-dithiolate, Nitrogen donors, Mixed ligand complexes.

\section{Introduction}

The coordination chemistry of transition as well as non-transition metal dithiolates has been an area of interest for several decades [1,2]. Recently, the role of dithio ligands has been explored in the design of many electrically conducting molecular solids [3-6]. The interest in this area stems from various reasons such as stabilization of transition metal ions in its unusual oxidation states, facile redox behaviour, stabilization of square planar geometry around transition metal ions, interesting spectral and magnetic properties. In addition, metal dithiolates have a large number of industrial and biological applications [2,7].

1,1-Dicyanoethylene-2,2-dithiolate ion, shows exciting coordination properties by virtue of their chelating and bridging behaviours which have been found in their binary, ternary and heterobimetallic complexes [2, 8-10]. Our earlier communications [11-15,16,17] include the studies on mixed ligand complexes of $\mathrm{Co}(\mathrm{II}), \mathrm{Ni}(\mathrm{II}), \mathrm{Cu}(\mathrm{II}), \mathrm{Zn}(\mathrm{II})$ and $\mathrm{Cd}(\mathrm{II})$ with some nitrogen donors and 1,1-dithiolates. McCleverty et. al. [18] has also reported mixed ligand complexes of Co(II) involving 1,1- and 1,2-dithiolates.

It is evident from the literature survey that there is no report on mixed ligand complexes of cobalt(II) with 1,1-dicyanoethylene-2,2-dithiolate ion and heterocyclic nitrogen donors. Thus, it was thought of interest to undertake the synthesis and spectrochemical characterization of mixed ligand complexes of cobalt(II) ion with 1,1- dicyanoethylene-2, 2-dithiolate (i-MNT ${ }^{2-}$ ) ion and heterocyclic nitrogen donors, 1,10-phenanthroline or 2,2'-bipyridine and investigate their reactivity towards heterocyclic nitrogen donors, such that pyridine (py), $\alpha$-picoline $(\alpha$-pic), $\beta$-picoline ( $\beta$-pic) or $\gamma$-picoline $(\gamma$-pic)]. The results of these investigations are reported in this article.

\subsection{Materials}

\section{Experimental}

All the chemicals used in this study were obtained from E. Merck of GR grade or equivalent quality. $\alpha-, \beta-$ and $\gamma$-picolines were obtained from Aldrich chemical company.

\subsection{Analysis of the complexes}

The complexes thus obtained were analyzed for cobalt using standard literature procedures [20]. Carbon, hydrogen and nitrogen were determined micro-analytically on CE 440 Exeter, USA and sulphur was estimated as $\mathrm{BaSO}_{4}$ gravimetrically. The water molecules were determined by heating the sample for $4 \mathrm{~h}$ in an electric oven maintained at $110-200^{\circ} \mathrm{C}$ and determining the loss of weight. 


\subsection{Physical Measurements}

The molar conductance of the millimolar solutions of the complexes in DMF was measured using Systronics direct reading conductivity meter 304 with a dip-type cell with platinized electrodes. Magnetic susceptibility measurements were made at room temperature on Cahn-Faraday electro balance using $\left[\mathrm{CoHg}(\mathrm{SCN})_{4}\right.$. Experimental magnetic susceptibility values have been corrected for diamagnetism by the procedures given by Figgis and Lewis [21] and Earnshaw [22]. Infrared spectra were recorded in nujol (4000-200 $\left.\mathrm{cm}^{-1}\right)$ and in $\mathrm{KBr}$ pellets $\left(4000-400 \mathrm{~cm}^{-1}\right.$ ) on a Bomem DA -8 FT-IR spectrophotometer using CsI and $\mathrm{KBr}$ optics, respectively. The electronic spectra of the complexes were recorded in the range 1100-200 nm on a Perkin-Elmer Model Lamda-25 UV-Vis spectrophotometer in DMF solution. Analytical data together with colour, magnetic moment and molar conductance values are presented in Table 1. Important electronic and infrared spectral data are given in Table 2 and Table 3, respectively.

\subsection{Preparation of ligands}

The potassium-1,1-dicyanoethylene-2,2-dithiolate $\left(\mathrm{K}_{2} \mathrm{i}-\mathrm{MNT} . \mathrm{H}_{2} \mathrm{O}\right)$ was prepared by a known literature procedure [19].

\subsection{Preparation of Co(o-phen $)_{2}(\mathrm{i}-\mathrm{MNT})$ (1)}

A $25 \mathrm{~cm}^{3}$ ethanol solution of , 1,10-phenanthroline)(o-phen) $(0.9911 \mathrm{~g}, 5 \mathrm{mmol})$ was added with stirring to a $25 \mathrm{~cm}^{3}$ aqueous solution containing hydrated cobalt(II) nitrate $(0.7276 \mathrm{~g}, 2.5 \mathrm{mmol})$ resulting orange coloured solution. To this resulting solution, a $25 \mathrm{~cm}^{3}$ aqueous solution of $\mathrm{K}_{2} \mathrm{i}-\mathrm{MNT} . \mathrm{H}_{2} \mathrm{O}(0.5909 \mathrm{~g}, 2.5 \mathrm{mmol})$ was added with stirring which yielded reddish brown precipitate. The precipitate was suction filtered, washed with water, alcohol, ether and dried in vacuo over fused $\mathrm{CaCl}_{2}$. After drying, the colour of the product was brown.

Attempt was made to synthesize $\mathrm{Co}(o \text {-phen })_{3}(\mathrm{i}-\mathrm{MNT})$ by taking $\mathrm{Co}(\mathrm{II})$ salt, $o$-phen and $\mathrm{K}_{2} \mathrm{i}-\mathrm{MNT} \cdot \mathrm{H}_{2} \mathrm{O}$ in 1:3:1 molar ratio respectively under the same conditions but the product obtained was $\operatorname{Co}(o-\text { phen })_{2}(\mathrm{i}-\mathrm{MNT})$.

\subsection{Preparation of $\mathrm{Co}(\mathrm{bipy})_{2}(\mathrm{i}-\mathrm{MNT})(2)$}

A quantity of 2,2-bipyridine (bipy) $(1.5619 \mathrm{~g}, 10 \mathrm{mmol})$ was added to a $150 \mathrm{~cm}^{3}$ of aqueous solution containing hydrated cobalt(II) nitrate $(1.4552 \mathrm{~g}, 5 \mathrm{mmol})$ and stirred the mixture which resulted wine red solution. To this solution, a $50 \mathrm{~cm}^{3}$ aqueous solution of $\mathrm{K}_{2} \mathrm{i}-\mathrm{MNT} \cdot \mathrm{H}_{2} \mathrm{O}(1.1819 \mathrm{~g}, 5 \mathrm{mmol})$ was added with stirring giving olive green precipitate. The precipitate was suction filtered, washed with water, alcohol, ether and dried in vacuo over fused $\mathrm{CaCl}_{2}$. After drying, the colour of the product was brown. After drying the colour of product turned to brown.

Attempt was made to synthesize $\mathrm{Co}(\text { bipy })_{3}(\mathrm{i}-\mathrm{MNT})$ by taking $\mathrm{Co}(\mathrm{II})$ salt, bipy and $\mathrm{K}_{2} \mathrm{i}-\mathrm{MNT} \cdot \mathrm{H}_{2} \mathrm{O}$ in $1: 3: 1$ molar ratio under the same conditions was unsuccessful.

\subsection{Preparation of $\mathrm{Co}(\mathrm{o}-\mathrm{phen})(\mathrm{i}-\mathrm{MNT}) .2 \mathrm{H}_{2} \mathrm{O}$ (3)}

A $20 \mathrm{~cm}^{3}$ ethanol solution of 1,10-phenanthroline $)(o$-phen $)(0.9911 \mathrm{~g}, 5 \mathrm{mmol})$ was added with stirring to a $20 \mathrm{~cm}^{3}$ ethanol solution containing hydrated cobalt(II) nitrate $(1.4552 \mathrm{~g}, 5 \mathrm{mmol})$ resulting yellow solution. To this resulting solution, a $20 \mathrm{~cm}^{3}$ aqueous solution of $\mathrm{K}_{2} \mathrm{i}-\mathrm{MNT} \cdot \mathrm{H}_{2} \mathrm{O}(1.1819 \mathrm{~g}, 5 \mathrm{mmol})$ was added with stirring resulted olive green precipitate. The precipitate was suction filtered, washed with water, alcohol, ether and dried in vacuo over fused $\mathrm{CaCl}_{2}$.

\subsection{Preparation of $\mathrm{Co}($ bipy $)(\mathrm{i}-\mathrm{MNT}) .2 \mathrm{H}_{2} \mathrm{O}(4)$}

The complex, Co(bipy)(i-MNT). $2 \mathrm{H}_{2} \mathrm{O}$ was prepared similar to $\mathrm{Co}(\mathrm{o}-\mathrm{phen})(\mathrm{i}-\mathrm{MNT}) \cdot 2 \mathrm{H}_{2} \mathrm{O}$ by taking $\mathrm{Co}(\mathrm{II})$ salt, 2,2'-bipyridine(bipy) and $\mathrm{K}_{2} \mathrm{i}-\mathrm{MNT} . \mathrm{H}_{2} \mathrm{O}$ in 1:1:1 molar ratio. The colour of precipitate found was olive green.

\subsection{Preparation of Co(o-phen)(i-MNT)(py $)_{2}$ (5)}

Co(o-phen $)(i-M N T) .2 \mathrm{H}_{2} \mathrm{O}(0.8306 \mathrm{~g}, 2 \mathrm{mmol})$ was added to $25 \mathrm{~cm}^{3}$ of pyridine slowly with vigorous shaking which resulted dark solution. The solution was filtered which did not yield any precipitate. The filtrate was evaporated naturally for a month, leaving a microcrystalline black product which was washed with ether containing traces of pyridine several times, suction filtered and air dried.

\subsection{Preparation of $\operatorname{Co}(o-p h e n)\left(i-M N T(\alpha-p i c / \gamma \text {-pic })_{2}(6,7)\right.$}

The blackish brown complex, Co(o-phen)(i-MNT) $(\alpha \text {-pic })_{2}$ and Co(o-phen)(i-MNT $(\gamma \text {-pic })_{2}$ were obtained essentially by the same method used for synthesis of $\mathrm{Co}(\mathrm{o}-\mathrm{phen})(\mathrm{i}-\mathrm{MNT})(\mathrm{py})_{2}$, only replacing pyridine by $\alpha$-picoline and $\gamma$-picoline respectively. 


\subsection{Preparation of Co(bipy)(i-MNT (py/a-pic/ $\gamma$-pic) $)_{2}(8,9,10)$}

Co(bipy)(i-MNT). $2 \mathrm{H}_{2} \mathrm{O}(0.7826 \mathrm{~g}, 2 \mathrm{mmol})$ was added sowly to $25 \mathrm{~cm}^{3}$ of pyridine / $\alpha$-picoline / $\gamma$-picoline with constant stirring yielding dark solutions. The solution was filtered and filtrate was allowed to evaporated naturally for a month, leaving blackish green product.

The product was washed several times with ether containing traces of corresponding bases, suction filtered and air dried.

\subsection{Preparation of Co(o-phen/bipy)(i-MNT)( $\beta$-pic $)_{2}(11,12)$}

$\mathrm{Co}(o-p h e n)(i-M N T) .2 \mathrm{H}_{2} \mathrm{O}(0.8306 \mathrm{~g}, 2 \mathrm{mmol})$ and $\mathrm{Co}(\mathrm{bipy})(\mathrm{i}-\mathrm{MNT}) \cdot 2 \mathrm{H}_{2} \mathrm{O}(0.7826 \mathrm{~g}, 2 \mathrm{mmol})$ was dissolved in $20 \mathrm{~cm}^{3}$ of DMF followed by addition of $\beta$-picoline $\left(\beta\right.$-pic) $\left(10 \mathrm{~cm}^{3}\right)$ with stirring. The solution was evaporated naturally and after 6 months a dark colour product was obtained, which was washed with ether several times yielding olive green/ blackish green powder respectively. The products were suction filtered and air dried.

\section{Results and discussion}

The analytical data indicate the formation of mixed ligand complexes of cobalt(II) of the compositions $\mathrm{Co}(\mathrm{N}-\mathrm{N})_{2}(\mathrm{i}-\mathrm{MNT}), \mathrm{Co}(\mathrm{N}-\mathrm{N})(\mathrm{i}-\mathrm{MNT}) \cdot 2 \mathrm{H}_{2} \mathrm{O}$ and $\left.\mathrm{Co}(\mathrm{N}-\mathrm{N})(\mathrm{i}-\mathrm{MNT}) \mathrm{L}_{2}\right][\mathrm{N}-\mathrm{N}=1,10$-phennthroline $(o$-phen $)$ or $2,2^{\prime}$-bipyridine (bipy); i-MNT ${ }^{2-}=1,1$-dicyanoethylene-2,2-dithiolate ; $\mathrm{L}=$ pyridine(py), $\alpha$-picoline $(\alpha$-pic), $\beta$-picoline $(\beta$-pic) or $\gamma$-picoline $(\gamma$-pic)].

The complexes do not decompose up to $200^{\circ} \mathrm{C}$ and are insoluble in water and common organic solvents (methanol, ethanol, chloroform, carbon tetrachloride, acetone, benzene etc) but soluble in coordinating solvents such as DMF and DMSO. These complexes cannot be re-crystallized but TLC measurements confirm the purity of the complexes as only one spot was observed for each complex.

The weight loss experiments for the complexes were carried out by heating a small amount of sample in a glass tube for $4 \mathrm{hrs}$ in an electric oven maintained at $100,120,150$ and $180^{\circ} \mathrm{C}$. The complexes, $\mathrm{Co}(o$-phen $)(\mathrm{i}-\mathrm{MNT}) \cdot 2 \mathrm{H}_{2} \mathrm{O}$ and $\mathrm{Co}$ (bipy)(i-MNT) $2 \mathrm{H}_{2} \mathrm{O}$ show loss of weight in the temperature range $150-180^{\circ} \mathrm{C}$ corresponding to two water molecules suggesting that they possess two water molecules in their coordination sphere.

\subsection{Molar conductance}

The low molar conductance values $\left(15.5-27.0 \mathrm{ohm}^{-1} \mathrm{~cm}^{2} \mathrm{~mole}^{-1}\right)$ in DMF solution $\left(10^{-3} \mathrm{M}\right)$ for complexes $(2-7,11)$ indicate non-electrolytes while values $\left(51.0-74.0 \mathrm{ohm}^{-1} \mathrm{~cm}^{2} \mathrm{~mole}^{-1}\right)$ for complexes $(1,8-10,12)$ indicate (1:1) electrolytic nature [23].

\subsection{Magnetic moment}

Magnetic susceptibility measurements and the electronic spectra of complexes were recorded for ascertaining the stereochemistry around $\mathrm{Co}(\mathrm{II})$ ion in these mixed ligand complexes. The corrected magnetic moments of Cobalt(II) complexes with $\mathrm{i}-\mathrm{MNT}^{2-}$ and heterocyclic nitrogen donors lie in the range 2.0 - 3.3 B.M. suggesting low-spin, $\mathrm{Co}(\mathrm{II})\left(\mathrm{t}_{2 \mathrm{~g}} \mathrm{e}_{\mathrm{g}}{ }^{1}\right)$, distorted octahedral stereochemistry around the Co(II) ion in these complexes. The observed $\left(\mu_{\text {eff }}\right)$ value is higher than calculated by the spin only formula $\left(\mu_{\mathrm{s}}\right)$ value. This suggests that there is also an orbital contribution.

\subsection{Electronic spectra}

In the electronic spectra of $\mathrm{Co}(\mathrm{II})$ complexes, there is a quartet ground state and three spin - allowed electronic transitions to the excited quartet states, ${ }^{4} \mathrm{~T}_{1 \mathrm{~g}}(\mathrm{~F}) \rightarrow{ }^{4} \mathrm{~T}_{2 \mathrm{~g}}\left(v_{1}\right)$, (generally occurs in the near i.r. region), ${ }^{4} \mathrm{~T}_{1 g}(\mathrm{~F}) \rightarrow{ }^{4} \mathrm{~A}_{2 g}\left(v_{2}\right)$ and ${ }^{4} \mathrm{~T}_{1 g}(\mathrm{~F}) \rightarrow{ }^{4} \mathrm{~T}_{1 g}(\mathrm{P})\left(v_{3}\right)$ are possible. The visible spectrum is dominated by highest energy transition ${ }^{4} \mathrm{~T}_{\mathrm{gg}}(\mathrm{F}) \rightarrow{ }^{4} \mathrm{~T}_{\mathrm{lg}}(\mathrm{P})$. Usually the ${ }^{4} \mathrm{~A}_{2 \mathrm{~g}}$ level is usually close to the ${ }^{4} \mathrm{~T}_{1 \mathrm{~g}}(\mathrm{P})$ level, so transitions to these two levels are close in energy. Since the ${ }^{4} \mathrm{~A}_{2 \mathrm{~g}}$ state is derived mainly from a $\mathrm{t}_{2 \mathrm{~g}} \mathrm{e}_{\mathrm{g}}{ }_{\mathrm{g}}$ electronic configuration and the ${ }^{4} \mathrm{~T}_{1 \mathrm{~g}}(\mathrm{~F})$ ground state is derived mainly from a $\mathrm{t}_{2 \mathrm{~g}} \mathrm{5}_{\mathrm{g}}{ }^{2}$ configuration, the ${ }^{4} \mathrm{~T}_{1 \mathrm{~g}}(\mathrm{~F}) \rightarrow{ }^{4} \mathrm{~A}_{2 \mathrm{~g}}$ transition is essentially a two-electron process and weaker than the other transitions. The electronic spectra of mixed ligand complexes of $\mathrm{Co}$ (II) have been discussed in the light of earlier studies $[\mathbf{2 4 , 2 5 , 2 6 ]}$.

The electronic spectra of complexes in DMF solution show three bands in the ranges 10141-11111, 16611-16694 and $21186-238089 \mathrm{~cm}^{-1}$ assignable to ${ }^{4} \mathrm{~T}_{1 \mathrm{~g}}(\mathrm{~F}) \rightarrow{ }^{4} \mathrm{~T}_{2 \mathrm{~g}}\left(\mathrm{v}_{1}\right),{ }^{4} \mathrm{~T}_{1 \mathrm{~g}}(\mathrm{~F}) \rightarrow{ }^{4} \mathrm{~A}_{2 \mathrm{~g}}\left(\mathrm{v}_{2}\right) \quad$ and ${ }^{4} \mathrm{~T}_{1 \mathrm{~g}}(\mathrm{~F}) \rightarrow{ }^{4} \mathrm{~T}_{\mathrm{lg}}(\mathrm{P})\left(v_{3}\right)$, respectively suggesting distorted octahedral stereochemistry around $\mathrm{Co}(\mathrm{II})$ in its complexes. The $v_{1}$ and $v_{2}$ bands are weak bands with respect to splitting of the third band reflects distortion in octahedral stereochemistry in these complexes. The $v_{1}$ and $v_{2}$ bands are of weak intensity with respect to $v_{3}$ band. The $v_{3}$ band in these complexes is not very distinct as obscured by the tail of the ligand absorption band.

The nujol-mull reflectance spectra of the complexes are not well resolved but most of the complexes show similar trends. 


\subsection{Infrared spectra}

IR spectra of the mixed ligand complexes have been interpreted in the light of earlier investigations $[\mathbf{1}, \mathbf{1 9}, \mathbf{2 7 - 3 2}]$ on transition and non transition metal 1,1-dithiolates. The i-MNT ${ }^{2-}$ ligand may be described by the following resonating structures as shown in Fig. 1 in which Fig 1(a) be the dominant resonating form in all the newly synthesized complexes.<smiles>N#CC(C#N)=C1CS1</smiles>

(a)<smiles>N#CC(=C=N)C1=NS1</smiles>

(b)<smiles>N=C=C(C=[W])C1=[SH]C=[14CH]1</smiles>

(c)

Fig. 1: Resonance forms of i-MNT ${ }^{2-}$ ligand ion.

Each of the moieties in the complexes undergoes particular vibrations and contributes certain peaks to their i.r. spectra. The electron delocalization in the chelated $\mathrm{i}-\mathrm{MNT}^{2-}$ ring leads to the coupling of vibrational modes so that few bands in i.r. spectra represent pure vibrations. IR spectra display characteristic stretching frequencies associated with $\mathrm{C} \equiv \mathrm{N}, \mathrm{C}=\mathrm{C}, \mathrm{C}-\mathrm{S}$ and $\mathrm{M}-\mathrm{S}$ from complexes of i-MNT ${ }^{2-}$; aryl ring vibrations with metal heterocyclic nitrogen vibrations from $o$-phen, bipy, py, $\alpha$-pic, $\beta$-pic and $\gamma$-pic .

The $v(\mathrm{C} \equiv \mathrm{N})$ band appearing at $2195 \mathrm{~cm}^{-1}$ with a shoulder at $2200 \mathrm{~cm}^{-1}$ in $\mathrm{K}_{2} \mathrm{i}-\mathrm{MNT} \cdot \mathrm{H}_{2} \mathrm{O}$, is a sharp absorption band and is found in the range $2197-2204 \mathrm{~cm}^{-1}$ in the mixed ligand complexes. The $v(C=C)$ absorption in all the complexes appears in the range $1381-1425 \mathrm{~cm}^{-1}$ observed in free $\mathrm{K}_{2} \mathrm{i}-\mathrm{MNT}$ ligand at $1360 \mathrm{~cm}^{-1}$, implying delocalization of $\pi$-electron out of the $C=C$ bond. In most of the complexes $v(C=C)$ was splitted band (doublet or triplet) indicating lowering of symmetry. The positive shifts observed in stretching frequencies of $\mathrm{C} \equiv \mathrm{N}$ and $\mathrm{C}=\mathrm{C}$ support resonance form (a) (Fig.1) as dominant in these complexes . A band at $960 \mathrm{~cm}^{-1}$ with a shoulder at $985 \mathrm{~cm}^{-1}$ in the i.r. spectrum of $\mathrm{K}_{2} \mathrm{i}-\mathrm{MNT} \mathrm{H}_{2} \mathrm{O}$ due to $=\mathrm{CS}_{2}$ group is found in the range $939-967 \mathrm{~cm}^{-1}$ in the complexes. The $v(\mathrm{C}-\mathrm{S})$ band occurring in the spectrum of $\mathrm{K}_{2} \mathrm{i}-\mathrm{MNT} . \mathrm{H}_{2} \mathrm{O}$ at $860 \mathrm{~cm}^{-1}$ appears as a single band in the range $876-903 \mathrm{~cm}^{-1}$ in the complexes indicating symmetrical bonding of both the sulphur atoms to metal ion. Similar bonding behaviour of i-MNT ${ }^{2-}$ ion is reported [28] in $\mathrm{K}_{2}\left[\mathrm{Ni}(\mathrm{i}-\mathrm{MNT})_{2}\right]$ where a single $\mathrm{v}(\mathrm{C}-\mathrm{S})$ band is observed at $900 \mathrm{~cm}^{-1}$.

Mixed ligand complexes show heterocyclic in-plane and out-of-plane ring deformation bands in the ranges 604-632and 425-435 $\mathrm{cm}^{-1}$, respectively indicating coordination through nitrogen atom as these bands show positive shifts with respect to the corresponding bands in the free form. Complexes, 3 and 4, show a broad bands in the region 3200-3500 $\mathrm{cm}^{-1}$ which are due to $v(\mathrm{O}-\mathrm{H})$. The weight loss experiment shows weight loss corresponding to two water molecules in each complex, 3 and 4 , above $180^{\circ} \mathrm{C}$ indicates the presence of coordinated water in these complexes. The $v(\mathrm{C}-\mathrm{H})$ (aromatic ring) arising from aromatic ligands in these complexes is observed as weak band(s) in the region $3000-3100 \mathrm{~cm}^{-1}$. The $v(\mathrm{C}-\mathrm{H})$ (aliphatic) for complexes containing $\alpha$-pic, $\beta$-pic or $\gamma$-pic is observed as very weak intensity bands in the region $2820-2950 \mathrm{~cm}^{-1}$ suggesting their presence in the mixed ligand complexes.

The non-ligand bands observed in the ranges 330-430 and $255-330 \mathrm{~cm}^{-1}$ in the complexes are tentatively assigned to $v(\mathrm{M}-\mathrm{N})[30]$ and $v(\mathrm{M}-\mathrm{S})[33]$ modes respectively.

Based on stoichiometries and above mentioned studies distorted octahedral stereochemistry around the cobalt(II) ion for these complexes have been proposed.

\section{Reactivity of the complexes}

The reactions of heterocyclic nitrogen donors (py, $\alpha$-pic, $\beta$-pic or $\gamma$-pic ) with $\mathrm{Co}\left(o\right.$-phen/bipy)(i-MNT). $2 \mathrm{H}_{2} \mathrm{O}$ were studied separately under different conditions then they yielded addition products of the composition $\operatorname{Co}\left(o\right.$-phen/bipy)(i-MNT) $\mathrm{L}_{2}[\mathrm{~L}=$ pyridine $(\mathrm{py}), \alpha$-picoline $(\alpha$-pic), $\beta$-picoline $(\beta$-pic) or $\gamma$-picoline $(\gamma$-pic)] approving the Lewis acid character of the mixed ligand complexes.

\section{Acknowledgements}

One of the corresponding author, Dr. Arijit Das, Principal Investigator of the SERB, DST Project, Govt. of India, is grateful to the SERB, DST, New Delhi, Govt. of India, for their financial assistance (Sanction no - SERB/F/5537/2013-14 dated 27/11/2013 and D.O. No. SB/EMEQ-014/2013). Dr. Arijit Das would also be grateful to Prof. (Dr.) Debabrata Goswami, Principal of the Ramthakur College, Agartala, Tripura (w), Tripura, India for his valuable sustaining mentality in this regard. 


\section{References}

[1] D. Coucouvanis, Prog. Inorg. Chem., 11, 26, 1970, 1979, 233, 301.

[2] R.P. Burns, F.P. McCullough and C.A. McAuliffe, Adv. in Inorg. Chem.. and Radiochem., 22, 1979, 303; 23, $1980,211$.

[3] J.A. McCleverty, Molecular Metals, Plenum, New York, 1979.

[4] M. Bousseau, L. Valade, J.P. Legros, P. Cassoux, M. Garbauskas and L. V. Interante J. Am. Chem. Soc., 108, 1986, 1908.

[5] A. Kobayashi, Y. Sasaki, R. Kato and H. Kobayashi, Chem. Lett., 387, 1986.

[6] D. Zhu, X.C. Xing, P.J. Wu, P. Wang, D.M. Zhang and D.L. Yang, Synth. Met., 42(3), $1991,541$.

[7] Chem. Abstr. 100, 1984, p115000 a ; 102, 1985, p31934m, p195283z; 104, p192920 k, 1986, p88608d ; 106, 1987, p67474 h.

[8] U. Abram, W. Dietzsch and R. Kirmse, Z. Chem., 22(8), 1982, 305.

[9] N.K. Singh, P.P. Aggarwal and N. Singh, Trans. Met. Chem., 15(4), 1990, 325 ; Synth. React. Inorg. Met.-Org. Chem., 21(4), 1991, 541.

[10] R.C. Aggarwal and R. Mitra, Indian. J. Chem., 33A, 1994, 55.

[11] M.K. Singh, R.C. Aggarwal and B. Singh, Synth. React. Inorg. Met.-Org. Chem., 15(4), 1985, 459.

[12] M.K. Singh, Indian J. Chem., 30A, 1991, $1070 ;$ 38A, 1999, 1294.

[13] M.K. Singh, J. Indian Chem. Soc., 76, 1999, 148

[14] M. K. Singh, A. Das and B. Paul, Trans. Met. Chem., 30(6), 2005, 655; 32(6), 2007, 732.

[15] M. K. Singh, A. Das, R. Laskar and B. Paul, J. Ind. Chem. Soc., 85, 2008, 1.

[16] M.K.Singh,A.Das and B.Paul, J. Coord. Chem., 62(16), 2009, 2745.

[17] M.K.Singh,A.Das, B.Paul, S.Bhattacharjee and S.Sutradhar, J. Ind. Chem. Soc., 89(3),2012, 421

[18] J.A. McCleverty, D.G. Orchard and K. Smith, J. Chem. Soc. (A), 1971, 707.

[19] K. A. Jensen and L. Henriksen, Acta Chem. Scand., 22, 1968, 1107.

[20] A.I. Vogel, A text Book of Quantitative Inorganic Analysis, $3^{\text {rd }}$ edit., ELBS and Longmans, London, 1961.

[21] .N. Figgis and J. Lewis, Modern Coordination Chemistry, Eds. J. Lewis and R.G.Wilkins, Interscience, New York, 1960.

[22] A. Earnshaw, Introduction to Magnetochemistry, Academic Press, London, 1968.

[23] W.J. Geary, Coord. Chem . Rev., 7, 1971, 81

[24] F.A. Cotton, G. Wilkinson, C.A. Murillo and M. Bochmann, Advanced Inorganic Chemistry, $6^{\text {th }}$ Edn., John Wiley and Sons, Inc, New York, 1999, 820.

[25] A.B.P. Lever, Inorganic Electronic Spectroscopy, Elsevier Publishing Company, New York, $1968,318$.

[26] M. Azam, I. ward, S. Al-Resayes, M. Zahin, I. Ahmad ad M. Shakir, Z. Anorg. Allg. Chem., 638(5), $2012,81$.

[27] M.L. Caffery and D. Coucouvanis, J. Inorg. Nucl. Chem., 37, 1975, 2081

[28] J. P. Fackler, Jr. and D. Coucouvanis, J. Am. Chem. Soc., 88, 1966, 3913.

[29] A. Davison, N. Edelstein, R. H. Holm and A. H. Maki, J. Am. Chem. Soc., 86, 1964, 2799.

[30] G.N. Schrauzer and V. P. Meyweg, J. Am. Chem. Soc., 87, 1965, 3585.

[31] D.M. Adams and J.B. Cornell, J. Chem. Soc. (A), 1967, 884.

[32] D.G. Turk and M.K. Yang, J. Chem. Soc. (A), 1971, 214

[33] K. Nakamoto, Infrared and Raman Spectra of Inorganic and Coordination Compounds, $3^{\text {rd }}$ Edn., Wiley - Interscience, New York, 1978.

Table 1. Analytical data, molar conductance and magnetic moments for the mixed ligand complexes of Co(II) ion.

\begin{tabular}{|c|c|c|c|c|c|c|c|c|}
\hline \multirow{2}{*}{$\begin{array}{l}\text { Complex } \\
\text { (colour) }\end{array}$} & \multirow{2}{*}{$\begin{array}{c}\% \text { yield } \\
\text { (Dec. } \\
\text { Temp. } \\
{ }^{0} \mathrm{C} \text { ) }\end{array}$} & \multicolumn{5}{|c|}{ Found (Calcd.), $\%$} & \multirow{2}{*}{$\begin{array}{l}\Lambda_{\mathrm{M}} \\
\left(\Omega^{-1} \mathrm{~cm}^{2}\right. \\
\mathrm{mol}^{-1} \\
(\mathrm{DMF})\end{array}$} & \multirow{2}{*}{$\begin{array}{c}\mu_{\text {eff }} \\
\text { (B.M.) }\end{array}$} \\
\hline & & Co & $S$ & $\mathrm{~N}$ & $\mathrm{C}$ & $\mathrm{H}$ & & \\
\hline $\mathrm{Co}(o \text {-phen })_{2}(\mathrm{i}-\mathrm{MNT})$ & $(270)$ & 10.19 & 11.41 & 14.83 & 59.82 & 2.32 & 51.00 & 3.30 \\
\hline (Olive green) & 72 & $(10.53)$ & $(11.45)$ & $(15.01)$ & $(60.10)$ & $(2.88)$ & & \\
\hline Co(bipy) $)_{2}(\mathrm{i}-\mathrm{MNT})$ & 70 & 10.97 & 12.44 & 15.92 & 55.84 & 3.02 & 27.00 & 2.80 \\
\hline (Greenish yellow) & $(220)$ & $(11-52)$ & $(12.53)$ & $(16.43)$ & $(56.36)$ & $(3.15)$ & & \\
\hline $\mathrm{Co}(o$-phen $)(\mathrm{i}-\mathrm{MNT}) \cdot 2 \mathrm{H}_{2} \mathrm{O}(3)$ & 65 & 15.53 & 16.30 & 12.99 & 45.92 & 2.62 & 23.00 & 2.90 \\
\hline (Olive green) & $(269)$ & $(14.18)$ & $(16.87)$ & (13.48) & $(46.26)$ & $(2.91)$ & & \\
\hline $\begin{array}{l}\mathrm{Co}(\text { bipy })(\mathrm{i}-\mathrm{MNT}) \cdot 2 \mathrm{H}_{2} \mathrm{O} \\
\text { (Olive green) }\end{array}$ & $\begin{array}{l}68 \\
(225)\end{array}$ & $\begin{array}{l}15.72 \\
(15.05)\end{array}$ & $\begin{array}{c}17.02 \\
(16.38)\end{array}$ & $\begin{array}{l}14.31 \\
(17.02)\end{array}$ & $\begin{array}{c}42.43 \\
(42.96)\end{array}$ & $\begin{array}{c}2.89 \\
(3.09)\end{array}$ & 19.00 & 2.95 \\
\hline $\begin{array}{l}\mathrm{Co}(o-\mathrm{phen})(\mathrm{i}-\mathrm{MNT})(\mathrm{py})_{2} \text { (5) } \\
(\text { Black) }\end{array}$ & $\begin{array}{c}72 \\
(240)\end{array}$ & $\begin{array}{c}10.36 \\
(10.96)\end{array}$ & $\begin{array}{c}11.90 \\
(11.92)\end{array}$ & $\begin{array}{c}15.21 \\
(15.63)\end{array}$ & $\begin{array}{c}57.85 \\
(58.09)\end{array}$ & $\begin{array}{c}3.12 \\
(3.37)\end{array}$ & 15.50 & 3.25 \\
\hline $\begin{array}{l}\mathrm{Co}(o \text {-phen })(\mathrm{i}-\mathrm{MNT})(\alpha-\mathrm{pic})_{2} \\
(\text { Blackish brown })\end{array}$ & $\begin{array}{l}77 \\
(242)\end{array}$ & $\begin{array}{c}10.61 \\
(10.41)\end{array}$ & $\begin{array}{c}10.90 \\
(11.33)\end{array}$ & $\begin{array}{c}14.32 \\
(14.85)\end{array}$ & $\begin{array}{c}58.97 \\
(59.46)\end{array}$ & $\begin{array}{l}3.45 \\
(3.92)\end{array}$ & 25.00 & 3.00 \\
\hline $\begin{array}{l}\mathrm{Co}(o \text {-phen })(\mathrm{i}-\mathrm{MNT})(\gamma-\mathrm{pic})_{2}(7) \\
(\text { Blackish brown })\end{array}$ & $\begin{array}{c}71 \\
(220)\end{array}$ & $\begin{array}{c}10.19 \\
(10.41)\end{array}$ & $\begin{array}{c}11.20 \\
(11.35)\end{array}$ & $\begin{array}{c}14.62 \\
(14.85)\end{array}$ & $\begin{array}{c}59.12 \\
(59.46)\end{array}$ & $\begin{array}{c}3.79 \\
(3.92)\end{array}$ & 20.00 & 2.00 \\
\hline $\begin{array}{l}\mathrm{Co}(\text { bipy })(\mathrm{i}-\mathrm{MNT})(\mathrm{py})_{2} \text { (8) } \\
\text { (Blackish green) }\end{array}$ & $\begin{array}{l}65 \\
(220\end{array}$ & $\begin{array}{c}10.99 \\
(11.47)\end{array}$ & $\begin{array}{c}12.02 \\
(12.48)\end{array}$ & $\begin{array}{c}16.02 \\
(16.36)\end{array}$ & $\begin{array}{c}55.87 \\
(56.13)\end{array}$ & $\begin{array}{c}3.13 \\
(3.53)\end{array}$ & 54.00 & 2.95 \\
\hline $\begin{array}{l}\mathrm{Co}(\text { bipy })(\mathrm{i}-\mathrm{MNT})(\alpha-\mathrm{pic})_{2} \\
\text { (Blackish green) }\end{array}$ & $\begin{array}{c}67 \\
(170)\end{array}$ & $\begin{array}{c}10.52 \\
(10.88)\end{array}$ & $\begin{array}{l}11.60 \\
(11.84)\end{array}$ & $\begin{array}{l}15.10 \\
(15,51)\end{array}$ & $\begin{array}{c}57.23 \\
(57.66)\end{array}$ & $\begin{array}{c}3.97 \\
(4.09)\end{array}$ & 61.00 & 2.90 \\
\hline $\begin{array}{l}\mathrm{Co}(\text { bipy })(\mathrm{i}-\mathrm{MNT})(\gamma-\mathrm{pic})_{2} \quad(\mathbf{1 0}) \\
(\text { Blackish green })\end{array}$ & $\begin{array}{c}70 \\
(214)\end{array}$ & $\begin{array}{r}10.48 \\
(10.88)\end{array}$ & $\begin{array}{c}11.37 \\
(11.84)\end{array}$ & $\begin{array}{l}15.23 \\
(15.51)\end{array}$ & $\begin{array}{c}57.35 \\
(57.66)\end{array}$ & $\begin{array}{l}3.87 \\
(4.09)\end{array}$ & 74.00 & 3.30 \\
\hline $\begin{array}{l}\mathrm{Co}(o-\text { phen })(\mathrm{i}-\mathrm{MNT})(\beta-\text { pic })_{2}(\mathbf{1 1}) \\
(\text { Olive green })\end{array}$ & $\begin{array}{c}70 \\
(230)\end{array}$ & $\begin{array}{c}10.22 \\
(10.41)\end{array}$ & $\begin{array}{c}11.00 \\
(11.33)\end{array}$ & $\begin{array}{l}14.63 \\
(14.85)\end{array}$ & $\begin{array}{c}59.01 \\
(59.46)\end{array}$ & $\begin{array}{l}3.58 \\
(3.92)\end{array}$ & 22.00 & 3.00 \\
\hline $\begin{array}{l}\mathrm{Co}(\text { bipy })(\mathrm{i}-\mathrm{MNT})(\beta-\mathrm{pic})_{2} \\
(\text { Blackish green })\end{array}$ & $\begin{array}{c}72 \\
(190)\end{array}$ & $\begin{array}{c}10.42 \\
(10.88)\end{array}$ & $\begin{array}{c}11.36 \\
(11.84)\end{array}$ & $\begin{array}{l}15.33 \\
(15.51)\end{array}$ & $\begin{array}{l}57.08 \\
(57.66)\end{array}$ & $\begin{array}{c}3.92 \\
(4.09)\end{array}$ & 60.00 & 2.92 \\
\hline
\end{tabular}


Table 2. UV-Vis data for the mixed ligand Complexes of Co(II) ion in DMF solution

\begin{tabular}{|c|c|c|c|c|}
\hline Complexes & ${ }^{4} \mathrm{~T}_{1 \mathrm{~g}}(\mathrm{~F}) \rightarrow{ }^{4} \mathrm{~T}_{2 \mathrm{~g}}$ & $\begin{array}{l}\lambda_{\max }(\mathbf{n m}), \boldsymbol{\varepsilon}(\mathbf{L} \mathbf{n} \\
{ }^{4} \mathrm{~T}_{1 \mathrm{~g}}(\mathrm{~F}) \rightarrow{ }^{4} \mathrm{~A}_{2 \mathrm{~g}}\end{array}$ & $\begin{array}{l}\left.\mathbf{0}^{\mathbf{F}^{-1}} \mathbf{c m}^{-1}\right) \\
{ }^{4} \mathrm{~T}_{1 \mathrm{~g}}(\mathrm{~F}) \rightarrow{ }^{4} \mathrm{~T}_{1 \mathrm{~g}}(\mathrm{P})\end{array}$ & Ligand bands \\
\hline $\mathrm{Co}(o \text {-phen })_{2}(\mathrm{i}-\mathrm{MNT})(\mathbf{1})$ & $986(20)$ & $601(203)$ & $436(1000)$ & 404(1966) \\
\hline $\mathrm{Co}(\text { bipy })_{2}(\mathrm{i}-\mathrm{MNT})(\mathbf{2})$ & - & $599(209)$ & $460(98)$ & 403(1970) \\
\hline $\mathrm{Co}(o$-phen $)(\mathrm{i}-\mathrm{MNT}) \cdot 2 \mathrm{H}_{2} \mathrm{O}(\mathbf{3})$ & - & $600(199)$ & $430(1800)$ & $365(1120), 302(1820)$ \\
\hline $\mathrm{Co}\left(\right.$ bipy)(i-MNT). $2 \mathrm{H}_{2} \mathrm{O}$ (4) & - & $599(207)$ & $465(900)$ & $398(1890)$ \\
\hline $\mathrm{Co}(o-\mathrm{phen})(\mathrm{i}-\mathrm{MNT})(\mathrm{py})_{2}(\mathbf{5})$ & $900(53)$ & $601(120)$ & $466(625), 436(1000)$ & $395(1808)$ \\
\hline $\operatorname{Co}(o-$ phen $)(\mathrm{i}-\mathrm{MNT})(\alpha-\mathrm{pic})_{2}$ & - & $600(259)$ & $459(1344)$ & 404(1970) \\
\hline $\mathrm{Co}(o-$ phen $)(\mathrm{i}-\mathrm{MNT})(\gamma-\mathrm{pic})_{2}(7)$ & - & $600(190)$ & $470(900)$ & 396(1996) \\
\hline $\mathrm{Co}($ bipy $)(\mathrm{i}-\mathrm{MNT})(\mathrm{py})_{2}(\mathbf{8})$ & $903(23)$ & $600(159)$ & $472(640)$ & 409 (1187) \\
\hline $\operatorname{Co}($ bipy $)(\mathrm{i}-\mathrm{MNT})(\alpha-\mathrm{pic})_{2}(\mathbf{9})$ & $900(12)$ & $602(178)$ & $460(702)$ & $415(1129)$ \\
\hline $\mathrm{Co}($ bipy $)(\mathrm{i}-\mathrm{MNT})(\gamma-\mathrm{pic})_{2}$ & $902(17)$ & - & $420(750)$ & $397(1700)$ \\
\hline $\operatorname{Co}(o$-phen $)(\mathrm{i}-\mathrm{MNT})(\beta \text {-pic })_{2}(\mathbf{1 1})$ & - & $601(175)$ & $432(820)$ & $395(1700)$ \\
\hline $\mathrm{Co}($ bipy $)(\mathrm{i}-\mathrm{MNT})(\beta-\mathrm{pic})_{2}$ & $900(16)$ & - & $445(725)$ & $396(1685)$ \\
\hline
\end{tabular}

Table 3. Characteristic i.r bands $\left(\mathrm{cm}^{-1}\right)$ for the mixed ligand complexes of Co(II) ion

\begin{tabular}{|c|c|c|c|c|c|c|}
\hline Complexes & $v(\mathrm{C} \equiv \mathrm{N})$ & $v(\mathrm{C}=\mathrm{C})$ & $v\left(=\mathrm{CS}_{2}\right)$ & $v(\mathrm{C}-\mathrm{S})$ & $v(\mathrm{M}-\mathrm{N})$ & $v(\mathrm{M}-\mathrm{S})$ \\
\hline $\mathrm{Co}(o \text {-phen })_{2}(\mathrm{i}-\mathrm{MNT})$ & $2197 \mathrm{vs}$ & $1408 v s$ & $944 w$ & $897 \mathrm{~s}$ & $430 \mathrm{w}$ & $255 \mathrm{w}$ \\
\hline $\mathrm{Co}(\text { bipy })_{2}(\mathrm{i}-\mathrm{MNT})$ & $2201 v s$ & $\begin{array}{l}1402 \mathrm{~s}, \\
1384 \mathrm{~s}\end{array}$ & $941 \mathrm{~m}$ & $897 \mathrm{~s}$ & $425 \mathrm{~m}$ & $265 \mathrm{w}$ \\
\hline $\mathrm{Co}(o$-phen $)(\mathrm{i}-\mathrm{MNT}) \cdot 2 \mathrm{H}_{2} \mathrm{O}$ & $2199 v s$ & $1382 \mathrm{vs}$ & $962 \mathrm{w}$ & $898 \mathrm{~m}$ & $428 \mathrm{~m}$ & $330 \mathrm{w}$ \\
\hline $\mathrm{Co}($ bipy $)(\mathrm{i}-\mathrm{MNT}) \cdot 2 \mathrm{H}_{2} \mathrm{O}$ & $2202 s$ & $\begin{array}{l}1405 \mathrm{vs} \\
1383 \mathrm{vs}\end{array}$ & $943 m$ & $899 m$ & $385 \mathrm{~m}$ & $328 w$ \\
\hline $\mathrm{Co}(o$-phen $)(\mathrm{i}-\mathrm{MNT})(\mathrm{py})_{2}$ & $2199 v s$ & $\begin{array}{l}1402 \mathrm{vs} \\
1382 \mathrm{vs}\end{array}$ & $940 \mathrm{~m}$ & $896 \mathrm{~m}$ & $350 \mathrm{~m}$ & $260 \mathrm{w}$ \\
\hline $\operatorname{Co}(o-$ phen $)(\mathrm{i}-\mathrm{MNT})(\alpha-\mathrm{pic})_{2}(\mathbf{6})$ & $2199 v s$ & $\begin{array}{l}1402 \mathrm{vs}, \\
1381 \mathrm{vs}\end{array}$ & $939 m$ & $895 \mathrm{~m}$ & $330 \mathrm{w}$ & $272 w$ \\
\hline $\mathrm{Co}(o$-phen $)(\mathrm{i}-\mathrm{MNT})(\gamma \text {-pic })_{2}$ & $2200 v s$ & $1426 \mathrm{~s}$ & $939 m$ & $876 \mathrm{~m}$ & $335 w$ & $274 w$ \\
\hline $\mathrm{Co}($ bipy $)(\mathrm{i}-\mathrm{MNT})(\mathrm{py})_{2}$ & 2196vs & $1384 v s$ & $956 \mathrm{~s}$ & $903 \mathrm{~s}$ & $365 \mathrm{~m}$ & $283 w$ \\
\hline $\operatorname{Co}($ bipy $)(\mathrm{i}-\mathrm{MNT})(\alpha-\mathrm{pic})_{2}$ & $2203 v s$ & 1394vs & $950 \mathrm{~m}$ & $903 \mathrm{~s}$ & $380 \mathrm{w}$ & $287 w$ \\
\hline $\operatorname{Co}($ bipy $)(\mathrm{i}-\mathrm{MNT})(\gamma-\mathrm{pic})_{2}$ & 2196vs & 1387 vs & $967 \mathrm{w}$ & $896 s$ & $375 w$ & $292 w$ \\
\hline $\operatorname{Co}(o$-phen $)($ i-MNT $)(\beta \text {-pic })_{2}(\mathbf{1 1})$ & $2200 v s$ & $1384 \mathrm{vs}$ & $939 m$ & $897 \mathrm{~s}$ & $340 \mathrm{w}$ & $302 w$ \\
\hline $\operatorname{Co}($ bipy $)(\mathrm{i}-\mathrm{MNT})(\beta-\mathrm{pic})_{2}$ & 2204vs & $1384 \mathrm{vs}$ & $944 m$ & $896 s$ & $376 w$ & $304 w$ \\
\hline
\end{tabular}

